\title{
Analysis on the Construction and Development of Human Capital Service Platform of Cultural and Creative Industry in the Age of Sharing Economy
}

\author{
Lingling Qu \\ School of Economics and Management \\ Leshan Normal University \\ Leshan, China 614000
}

\author{
Min Kuang \\ School of Economics and Management \\ Leshan Normal University \\ Leshan, China 614000
}

\begin{abstract}
A significant sign of the era of shared economy is the use of credit guarantees provided by the third-party platforms to turn idle products into services and share them with strangers, and product suppliers turn idle products into profits through sharing. Based on this feature, this paper proposes to combine the resources of the cultural and creative industries to build a human capital service platform. By using the "two" hand, combining the "two" lines, concentrating on the "two" focuses, and eliminating the "two" paradox to better connect the two sides of the demand in this way of achieving the great with doing little and to optimize the allocation of socialized market resources, with a view to continuously promoting "mass entrepreneurship and innovation" and revitalizing resources in the large context, and then, guiding the economy and driving economic development.
\end{abstract}

Keywords-sharing economy; cultural and creative industries; human capital; service platform; construction; development

\section{INTRODUCTION}

Long time ago, it is predicted that the twenty-first century will be a new era, but when this era comes, the changes of our lives are particularly surprising and horrifying. It seems that overnight, big data, "Internet + " have become part of our lives. "Online trading", "no cash payment", "quick sales" that used to exist only in the concept... all payment, trading, even lifestyle and thinking habits are very different from traditional ones. The people's social life changes brought by Internet have become more and more unexpected. The era of "sharing economy" has met us by chance.

The term "sharing" first refers to the exchange of items or messages with others. With the popularity and application of the Internet, gradually, all aspects of people's social and social life, whether it is tangible physical or intangible information exchange began to appear. Since 2008, Uber, Airbnb in foreign countries, domestic "Didi Taxi", "Kuaidi Taxi", "little piggy short-term rentals" and other physical sharing platforms have begun to appear successively. The sharing economy has finally made a substantial step from a concept to a reality. Through the credit guarantee provided by the third-party platform, the idle products can become services and be shared with strangers. The product suppliers turn the idle products into profits through sharing ${ }^{1}$, which has become a prominent label of the era of sharing economy. It is against this background that the cultural and creative industries seem to have ushered in their own springs. Things that seem impossible in the past, under the premise of "sharing", is gradually entering the people's business with the help of human capital service platform (third-party platform), and it is sure to more take part in our lives.

\section{CONSTRUCtion OF Human CAPITAL SERVICE} PLATFORM OF CULTURAL AND CREATIVE INDUSTRY IN THE AGE OF SHARING ECONOMY

With the advent of the digital age, the distance among people, among departments, among units, and even among countries seems to have shortened. The problem that used to go out and even run many different places to solve can now be solved and completed without leaving home. At the same time, it also makes people's require more professional documents, words and even literary talents. In this context, the cultural and creative industries have received unprecedented attention. If someone wants to apply for studying abroad, he needs to write a letter of recommendation, and if he plans to build up a company, he has to register the trademark. If these things are done in person, it will be a waste of energy and time; but for the companies specializing in intellectual property, once entrusted and paid, it's really a piece of cake for them... These are the problems that we often encounter in social production and life. How to enable competent people to provide reasonable help to those in need, and make sure that both sides' behaviors get certain constraints and supervision, and meanwhile, ensure authenticity and rigor are the original intention of the construction of human capital service platform of the cultural and creative industry.

\section{A. The Basis of Construction}

1) The appeal of the big data age: The fundamental feature of the sharing economy (also known as common economy and cooperative consumption) refers the economic

Ma Qiang. Development Status, Dilemmas and Countermeasures of Sharing Economy in China[J].Modern Economic Research, 2016(10): 20 
model of sharing goods, services, data or skills among different entities through the Internet platform ${ }^{2}$. Under such a model, it is indispensable that big data is the foundation for all platforms. Today's big data can provide people with more and better analysis of demand needs and initial integration of personal information. For example, in the shopping website, through big data analysis, Taobao users' shopping preferences can be analyzed and classified, and then targeted recommendations are made. Such a match will make people's needs more precise, and the problem solving will be more targeted. At the same time, for cultural and creative industry, it is more about the provision of services and skills, especially that for the intellectual property that has been being criticized. In the context of big data, combined with one-on-one transactions, it can play its role to the maximum and be protected as it should be. The era of big data is urgently calling for the emergence of the human capital service platform of cultural and creative industry.

2) The perfect fit of knowledge and economy: With the advent of the new round of world industrial revolution, the cultural and creative industry has become the new preference of economic transformation and reconstruction with its creativity and sustainability ${ }^{3}$. For this intangible intellectual capital, there was no effective platform to provide help for the demand side in the past; and many knowledge workers cannot convert their talents or skills into money to reflect their value. The human capital service platform of cultural and creative seeks to provide an effective way to maximize human capital and achieve a perfect combination of knowledge and corresponding economic benefits.

3) People-oriented new targeting: In the development of cultural and creative industries, the linkage of creativity, innovation and entrepreneurship is a key element of its sustainable development ${ }^{4}$.

And any part of these key elements cannot be separated from a subject - people. As an incubator of knowledge workers, the human capital service platform should be "peopleoriented." Party A of the platform - the provider of the service is the person; party B of the platform - the recipient of the service is also the person; the platform of the intermediary between the two parties is the link between the people. It refers that how to introduce the skills and knowledge of party A on the one hand; on the other hand, it is necessary to protect party B's rights and services, thereby achieving better social values. "Fig. 1"

\footnotetext{
Ma Qiang. Development Status, Dilemmas and Countermeasures of Sharing Economy in China[J].Modern Economic Research, 2016(10): 20

Zhang Xiaoming, Wang Jiaxin, Zhang Jiangang. The Report of China Cultural Industry Development (2015-2016) [M]. Beijing: Social Sciences Academic Press, 2016

Ma Xiulun. Cultural and Creative Industry Development and Talent Cultivation --- A Summary of the 2017 Cross-Strait Cultural and Creative Industry Undergraduate Skills Alliance Conference[J].Journal of Guangzhou Nanyang Technological Vocational College, 2017(09): 92-93
}

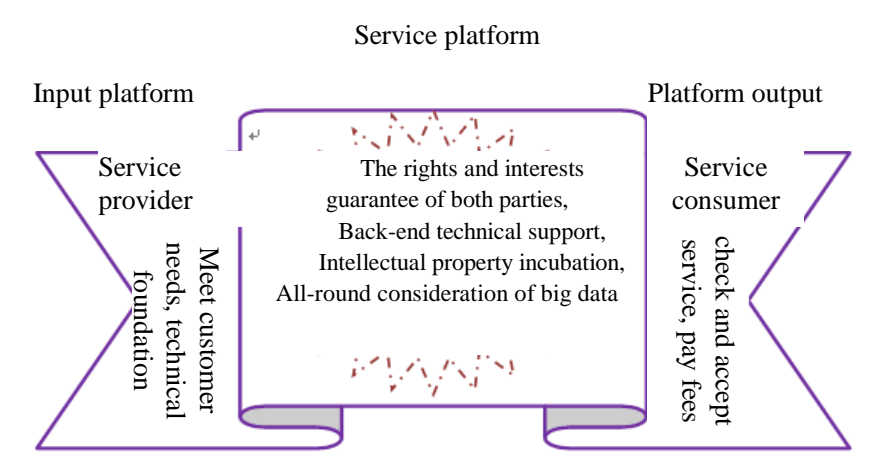

Fig. 1. The basic diagram for Human resources service platform construction of cultural and creative industries

\section{B. Features of the Platform --- Achieving the Great with Doing Little}

The human capital service platform of cultural and creative industry is a unique product of the era of sharing economy in the context of big data. Therefore, it also has its own typical and characteristics:

1) "Two" hands: The development of any industry is inseparable from the driving force behind it, and the two big hands of "government" and "market" play a pivotal role in the human capital service platform of cultural and creative industry. As many as 203 "peoples" in the 19th National Congress report reflecting that the state's concern for people's well-being has become the most important symbol of the new era. The new era also clarifies the new mission and development methodology of human capital service development ${ }^{5}$. For the first time, the report of the 19th National Congress put forward the concept of human capital service in the Party's highest document, and clarified that human capital service is the new growth point and new kinetic in the country's social and economic development. This is China's major theoretical innovation in the field of human capital services, and also a major industrial innovation based on the accurate judgment of the main contradictions of China's new era society and the essence of economic development ${ }^{6}$.From the international and domestic experience, the government's power to promote the development of cultural and creative industries cannot be ignored ${ }^{7}$. At the same time, the huge demand of the market is also an important part of the pull production. From the government purchasing services to the people gradually accepting online transactions, it can be easily found out that it is easy to improve production efficiency and save time on the human capital service platform. The "push" of the "government" and

\footnotetext{
Yang Weiguo. Innovation Promotes New Growth of Human Capital Services[J].Chinese Journal of Population Science, 2017(06): 2-3. Yang Weiguo. Innovation Promotes New Growth of Human Capital Services[J].Chinese Journal of Population Science, 2017(06): 2-3.

7 Wei Xin.Chengdu Has Ushered in the Best Period to Develop the Cultural and Creative Industry[N].Chengdu Daily, 2018(02): Edition 009.
} 
the "pull" of the "market" bring about economic development and the quality of life of ordinary people.

2) "Two" lines: At the same time, for the rapidly developing Internet era, there will be inevitably some discordant factors in their following footsteps. For example, the authenticity of information provided and the product, as well as the path and security of payment can not be guaranteed. As a service platform for human capital, pure online transactions do not seem to provide $100 \%$ trust to users. On-line is the trading market and employment business incubator. While carrying on online construction of the service platform, offline guarantees will also be provided. As the platform builder, the management departments and personnel are mainly concentrated off-line for forwardlooking predictions or post-sales guarantees. The existence of physical departments, entities and physical workstations will further enhance the user's confidence in use, while offline training and community building also contribute to the orderly development of the market.

3) "Two" targets: The sharing economy is also called "cooperative consumption". In addition to resource providers and resource recipients, this kind of cooperation needs to be supported by the concepts of "point-to-point" and "plane-toplane". To put it simply, "point-to-point" refers that as users of platform service, the communication between the seller and the buyer is accurate. From the search engine to the final result, users and sellers can save time and at the same time, the effective resources can be got. This kind of "point-topoint" is mainly a microscopic perspective, requiring the service platform to be more precise and mature at the time of construction. The "plane-to-plane" is a macro perspective. On the one hand, it breaks through the traditional one-to-one model. Instead, it will bring a large number of talents to a large number of employers through the platform, realizing massive trading of massive amounts; on the other hand, the results of the transaction and even the data analysis of the entire platform operation is not only used in inside the platform, but is to draw effective conclusions by statistics, cloud computing, algorithm driving, etc., and expand to a large number of different industries, regions and even larger modules to achieve perfect organic combination of business value and social value. In this way, the meaning of the sharing economy can be described vividly.

4) "Two" paradoxes: For a long time in the past, some scholars believed that the era of big data should reduce manpower as much as possible, and some even predicted that many people would face unemployment in the future. People who are still panicking have discovered a new round of opportunities in the mobile Internet era. With the new business model of sharing economy based on shared idle goods or services, the "mass entrepreneurship and innovation" put forward in the government work report is also ushering in a full-flowering season. The human capital service platform of the cultural and creative industry is a typical representative of intellectual property assembly protection. Whether it is the
"Zhuba Jie. com" with super-fast growth rate or the "Zhihu" that once refreshed the public perception have more and more got into people's life and have effectively solved the problem of human resource allocation that was originally a paradox.

\section{CONSTRUCTION OF HUMAN CAPITAL SERVICE PLATFORM OF CULTURAL AND CREATIVE INDUSTRY IN THE AGE OF SHARING ECONOMY}

In contrast, the era of sharing economy has laid the foundation for the human capital service platform of cultural and creative industry, it is better to say that the development of the human capital service platform of cultural and creative industry has adapted to this era.

\section{A. Value Analysis of Development}

1) Continuously promote "mass entrepreneurship and innovation":Mass entrepreneurship and innovation is a powerful driving force for economic development as well as a strong support for expanding social employment ${ }^{8}$. By sharing economy, the human capital service platform gathers talents to serve the transformation and upgrade of individuals, enterprises, and regional. For example, "ants short-term rental" and "Tujia" share the houses and serve tenants. The "Zhuba Jie. Com" share talents, intellectuals and serve entrepreneurs, companies and even regional economies... Compared with ordinary trading platforms, the human capital service platform highlights and emphasizes the role of "people" in the transaction process. In particular, the human capital service platform of the cultural and creative industry can not only solve the employment problem of ordinary people with entrepreneurial dreams in a large amount every year, but also maximize the mass innovation because of its novel and unique way of thinking and operation methods.

2) Revitalize resources: With the help of digital infrastructure, the human capital service platform of cultural and creative industry manages and maintains the operation by charging commissions to both parties. And when it comes to managing funds and talents, it has a strict custody and review system. The times that "nowhere to show encyclopedic mind" has been gone forever. With the fever of the sharing economy, the human capital service platform further revitalizes idle social resources and production factors and even those nowhere to find; the platform brings together professional talents and a large number of knowledge workers and forms a drilling platform of data ocean for market-oriented resource allocation.

\section{B. Key Elements of Development}

With the further construction and development of the human capital service platform of cultural and creative industry, there are also some key elements that need to be handled properly.

\footnotetext{
$8 \quad$ Wang Xiwen.Mass Entrepreneurship and Innovation and Sharing Economy[J].Chinese Cadres Tribune 2015(11): 12.
} 
1) Steadfast steps and firm willing: This is a new industry and one of the few economic platforms for knowledge sharing. In the process of development, any new thing will inevitably face obstacles and doubts. At the same time, there will always be various difficulties and contradictions. As a platform builder, on the one hand, it is necessary to consolidate technology and strengthen management; on the other hand, it should further improve the overall operation of the platform, and continue to have great aspiration in mind, and believe that the human capital service of cultural and creative industry will be a pervasive operation way of knowledge economy in the future. It's crucial to keep steadfast steps and firm willing.

2) Profit from evidence and seek for survival: The development of the platform should not be disorderly. It is necessary to learn from the experience of the predecessors and to abandon the bad habits of the past. From this perspective, learning is especially important. "Evidence-based management" refers to the way in which the management principles above scientific evidence management are transformed into organizational behavior. (MBA Think Tank Encyclopedia, 2016) Simply put, it is the process of turning scientific theory into action. The human capital service platform of cultural and creative industry finds the best evidence from the two aspects of "cultural and creative industry" and "human capital service" respectively, and then makes reasonable reference to the development of the platform, so that the platform construction has evidence to follow and make strong survival.

3) Innovation driven: If "entrepreneurship" is the cornerstone, then "innovation" should be a milestone for the continued development of the platform. With the vigorous development of innovative ideas, whether it is entrepreneurship or business, those people adept in innovation can win the competition. Whether it is inspirational innovation, theoretical innovation, technological and technological innovation, or results innovation ... abolishing the old and making innovation will occupy the market in the new era. This is even truer for the cultural and creative industries. "Good-looking skins are the same, and the souls of the interesting ones are one in ten thousand ${ }^{9}$." Production is valuable and creativity is priceless. The development of the platform always also takes this concept as a belief to pursue the continuous promotion of entrepreneurship with the core of innovation, and drive human capital services.

\section{CONCLUSION}

\section{A. Research Conclusion}

At present, as the knowledge economy sharing platform of the human capital service leader of the cultural and creative industry, "Zhuba Jie.com" created by Zhu Mingyue has done the best. As a massive information platform, the website publishes demands free of charge to attract talents. As of early May, 2018, it has found professionals for 101,371,108 employers. (Data from www.zbj.com May 13, 2018 16:43 real-time data report). With the power of the sharing economy, "Zhuba Jie.com" seized the opportunity and deepened innovation. In just a few years, it has expanded the online and offline services of the platform to several provinces and provincial capitals and 60 districts and counties. According to the number of website platforms and regional distribution maps displayed internally, it is also one of the largest cultural creative and online service trading platforms in China, as well as the leading platform supported by "mass entrepreneurship and innovation" in China. The success of "Zhuba Jie.com" tells people that the road to cultural power is a road to sustainable development, and when people recognize and appreciate the convenience and coziness of the cultural and creative industries for production and living services, the human capital service platform development has been on the line and ready to go. In the past, "Zhuba Jie.com" as the leader led the knowledge economy sharing to be a part of life. At the same time, it also eased the employment pressure to a certain extent, and further enhanced the entrepreneurial drive, making "mass entrepreneurship and innovation" no longer an empty talk, but is that the innovation and entrepreneurship that goes hand in hand. This is also the driving force for promoting the high-quality development of the economy, so as to better promote the high-quality life of the people. In the mean time, the original scattered talents are gathered through the sharing economy to effectively aggregate and improve the platform to serve the transformation and upgrading of the enterprise and the region.

\section{B. Management Enlightenment}

But it is necessary to realize that as an emerging industry, it will inevitably encounter all kinds of difficulties and unprecedented gaps. For example, about the platform's sharing services, the qualification review and authenticity judgment of both parties need to be further verified. In addition to the provision of documents, contact information, and financial guarantees, if conditions permit, VR portrait technology verification or AI system for the design of supervision can be introduced, which can prevent loopholes more effectively, ensure security and avoid unnecessary disputes. This is also the biggest hidden danger in the current network platform. In addition, in terms of ideology, both in the cognitive field and in the propaganda, it needs to be further strengthened. "This is the best era, but meanwhile, this is the worst era." The sharing economy gradually subverts and eliminates the old model and revitalizes different fields in new ways. The human capital service platform of the cultural and creative industry is prosperous due to it; therefore, only facing the sharing economy and making full use of the roles of the government and the market to promote the development of the capital service platform of the cultural and creative industries, can it better serve the public and serve the society in order to make China's economy transformation successful as soon as possible, and realize the Chinese dream of the country's prosperity,

\footnotetext{
Owl of Lao Yang. Good-looking Skins are the Same, and the Souls of the Interesting Ones are One in Ten Thousand[M]Modern Press 2018 (1):1.
} 
national rejuvenation, people's happiness and social harmony as soon as possible ${ }^{10}$.

\section{REFERENCES}

[1] Chen Xianfu, Yang Qiao. Research on the Integrated Development of Ma Qiang. Development Status, Dilemmas and Countermeasures of Sharing Economy in China[J].Modern Economic Research, 2016(10): 20, 24.

[2] Wang Xiwen. Mass Entrepreneurship and Innovation and Sharing Economy[J].Chinese Cadres Tribune2015(11):12.

[3] Yang Weiguo. Innovation Promotes New Growth of Human Capital Services[J].Chinese Journal of Population Science, 2017(06): 2-3.

[4] Ma Xiulun. Cultural and Creative Industry Development and Talent Cultivation ---- A Summary of the 2017 Cross-Strait Cultural and Creative Industry Undergraduate Skills Alliance Conference[J].Journal of Guangzhou Nanyang Technological Vocational College, 2017(09): 92-93

[5] Owl of Lao Yang. Good-looking Skins are the Same, and the Souls of the Interesting Ones are One in Ten Thousand[M]Modern Press2018 (1) $: 1$

[6] Zhang Xiaoming, Wang Jiaxin, Zhang Jiangang. The Report of China Cultural Industry Development (2015-2016) [M].Beijing:Social Sciences Academic Press, 2016.

[7] Wei Xin. Chengdu Has Ushered in the Best Period to Develop the Cultural and Creative Industry[N].Chengdu Daily, 2018(02): Edition 009.

10 Ma Qiang. Development Status, Dilemmas and Countermeasures of Sharing Economy in China[J].Modern Economic Research, 2016(10): 24. 